\title{
Trajeto de pessoas com deficiência à unidade de saúde da família
}

\author{
Path of persons with disabilities to family health unit
}

\author{
Vagner Ferreira do Nascimento', Walber Gineli de Jesus'², Bianca Carvalho da Graça², \\ Rosângela Aparecida Gonçalves ${ }^{2}$, Ana Cláudia Pereira Terças ${ }^{2}$, Thalise Yuri Hattori ${ }^{2}$ \\ 'Autor para correspondência. Departamento de Enfermagem, Universidade do Estado de Mato Grosso. Tangará da Serra, Mato Grosso, Brasil. \\ vagnerschon@hotmail.com \\ ${ }^{2}$ Departamento de Enfermagem, Universidade do Estado de Mato Grosso. Tangará da Serra, Mato Grosso, Brasil. \\ walbergineli_se@hotmail.com, biancacgraca@gmail.com, roose_76@hotmail.com, enfanacnp@gmail.com, thalisehattori@gmail.com
}

\begin{abstract}
RESUMO | OBJETIVO: conhecer o trajeto de pessoas com deficiência à unidade de saúde da família. MÉTODO: trata-se de estudo observacional, descritivo e qualitativo. A coleta de dados ocorreu no período entre novembro de 2015 e março de 2016, no maior bairro da periferia de um município da região médio norte de Mato Grosso, mediante roteiro de observação, fotografias, fita métrica e diário de campo. As imagens foram interpretadas pela análise iconográfica. RESULTADOS: o descuido e o desrespeito com as questões ética e ambiental de outros moradores ficaram evidentes no estudo, colaborando ou intensificando barreiras urbanísticas para inacessibilidades das pessoas com deficiência. Dentre as barreiras encontradas, predominou descontinuidade e empecilhos em calçadas. CONCLUSÃO: como forma de eliminar essas barreiras e promover maior inclusão social, fazem-se necessárias medidas de conscientização da população, práticas informativas sobre seus direitos e acolhimento integral, principalmente conduzidos por profissionais de saúde, além do olhar sensível dos órgãos gestores.
\end{abstract}

PALAVRAS-CHAVE: Acesso aos serviços de saúde. Pessoas com deficiência. Estruturas de acesso.

\begin{abstract}
OBJECTIVE: to assess and evaluate the path of people with disabilities to the Family Health Unit (Brazilian Public Health System). METHOD: this is an observational, descriptive and qualitative study. Data collection occurred between November 2015 and March 2016 in districts of the periphery of the largest municipality in the middle north of Mato Grosso state, Brazil, through observation script, photographs, tape measurements and field diaries. The images were interpreted by iconographic analysis. RESULTS: carelessness and disregard for the ethical and environmental issues of other residents were evident in the study, collaborating or intensifying urban barriers to inaccessibility of persons with disabilities. Among the barriers encountered, predominated discontinuity and obstacles on sidewalks. CONCLUSION: In order to eliminate these barriers and promote greater social inclusion are necessary public awareness policies, information practices of the rights of the people with disabilities and full compliance with the rights of people with disabilities, mainly driven by health professionals, and the sensitive eye of the management bodies.
\end{abstract}

KEYWORDS: Health services accessibility. Disabled persons. Architectural accessibility. 


\section{Introdução}

O termo acessibilidade corresponde à possibilidade e condição do alcance, percepção e compreensão, para usufruto, de forma segura e autônoma, de espaços, edificações, mobiliários, equipamentos, meios de transporte, comunicação, informação e demais serviços e/ou instalações que se encontrem abertos à população, de caráter público ou privado, de utilização coletiva, localizados na zona rural ou urbana, de pessoas com ou sem deficiência'.

Essa acessibilidade aplicada aos serviços de saúde direciona a dois aspectos: a dimensão sócio organizacional, que caracteriza a oferta do serviço e a dimensão geográfica, que se associa à distância e ao deslocamento ${ }^{2}$. Quando se trata das Unidades de Saúde da Família (USF), a pessoa com deficiência (PcD) se esbarra em muitas dificuldades, desde aquelas relacionadas à localização da unidade no território à outras referente às adequações necessárias para sua plena utilização ${ }^{3}$.

Segundo Mamed $^{4}$ o acesso aos serviços de saúde é designado como a autonomia de escolha dos serviços, bem como sua disponibilidade no instante da procura ou até mesmo como se dá a relação entre os pilares de aceitabilidade, disponibilidade e informação. Porém, essa clientela pode apresentar perda de sua autonomia e isso lhes causar danos na assistência à saúde, já que possuem sofrimentos históricos diante da invisibilidade e estigmatizações da sociedade 5 .

A oferta dos serviços de saúde não implica apenas em dispor de estruturas prediais voltadas ao cuidado em saúde, mas sim no modo como esse cuidado é compreendido e efetivado. A começar pela redução da distância entre o cliente, serviço e profissional, refletindo principalmente sobre suas necessidades e as barreiras existentes até o encontro assistencial.

Mas, ainda que haja assistência pelas equipes de USF, a busca por independência, liberdade e dignidade dessas pessoas deve ser prioridade no trabalho dos profissionais de saúde. Contudo, esse trabalho deve ser compartilhado com toda a comunidade, pois todos desfrutam das melhorias geradas 5 .

A partir disso, a afim de entender e superar algumas iniquidades em saúde, de caráter ambiental, esse estudo objetivou conhecer o trajeto de pessoas com deficiência à Unidade de Saúde da Família (USF).

\section{Metodologia}

Trata-se de estudo observacional ambiental, descritivo e qualitativo. Realizado na periferia do maior município da região do médio norte de Mato Grosso. A escolha deste município deu-se primeiramente por ser referência de 21 municípios mato-grossenses, possuir o maior quantitativo populacional dessa região e pela escassez de estudos dessa natureza in loco.

Primeiramente, antecedendo à coleta de dados, houve contato e reunião com as equipes de saúde da família das áreas escolhidas, a fim de apresentar-lhes 0 estudo e responder aos questionamentos frente ao seu desenvolvimento. Após, verificou-se disponibilidade de um agente comunitário de saúde (ACS) para apresentar a área de cobertura da unidade de saúde, sinalizar os trajetos das PcD.

Os dados foram coletados no período compreendido entre novembro a dezembro de 2015 no bairro mais distante do centro urbano desse município, por deduzir maiores desigualdades e vulnerabilidades. Utilizou-se roteiro de observação dos bairros e fotografias do principal trajeto das residências dos sujeitos até a USF da área através de câmera digital Sony Cyber-shot DSC-H100 $16.1 \mathrm{mp}$; fita métrica graduada em centímetros servindo como recurso para a mensuração de superfícies e diário de campo.

Utilizou-se a codificação do tipo alfanumérica, onde a letra $P$ indica o percurso do sujeito e o elemento numérico que compôs o conjunto, a ordem em que ocupa na pesquisa.

Dentre as imagens urbanísticas capturadas, selecionou-se aquelas que melhor retratavam os obstáculos encontrados. Estas foram tratadas pela análise conceitual, em três etapas de interpretação: a pré-iconográfica (nível primário ou natural), a iconográfica propriamente dita (secundário ou convencional) e o terceiro nível, mais profundo, centrado no significado intrínseco (ou conteúdo), que comporta uma demasia de valores simbólicos ${ }^{6}$. 
Respeitando todos os aspectos éticos em pesquisa desse caráter observacional ambiental, todas as imagens do estudo, apresentaram somente aspectos urbanísticos e arquitetônicos, consequentemente, não trouxeram nenhum prejuízo e/ou danos a seres humanos, bem como à natureza.

\section{Resultados e discussão}

A localidade do estudo situa-se a $6100 \mathrm{~m}$ de distância do centro do município, abrange uma média populacional de 4122 pessoas, sendo grande parte carente e amparada por programas de auxílio governamentais, residentes em moradias de alvenaria, com energia elétrica e abastecimento de água tratada, recolhimento de lixo em três distintos dias da semana, imperando o uso de fossa séptica como escoadouro. $O$ transporte coletivo circula pelo local a cada 60 minutos.

Entre os percalços predominantes nos trajetos investigados, destacou-se irregularidades presentes nas passarelas e calçadas.

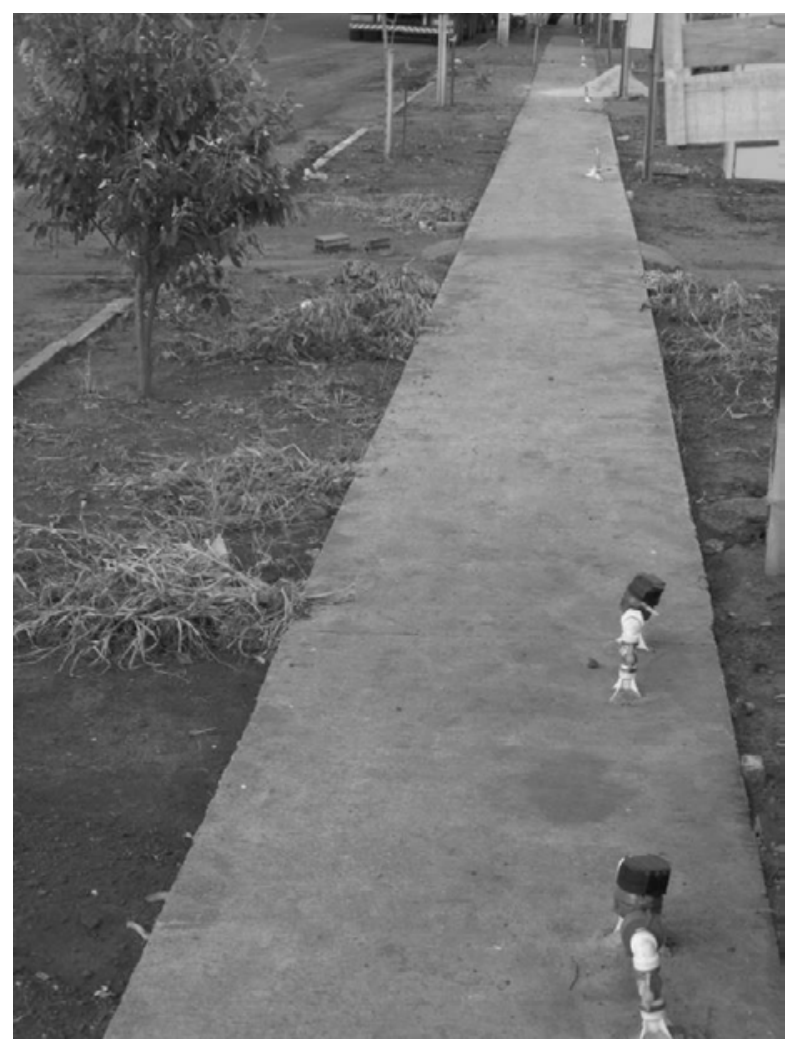

Figura 1. Hidrômetros no percurso P10. Novembro a dezembro de 2015. Tangará da Serra -MT, Brasil.
Na figura 1, observa-se hidrômetros dispostos centralmente à calçada da residência do P10, que além de dificultarem a passagem do sujeito, intensificam o sofrimento de cadeirantes nesse percurso, visto que ao manobrarem suas cadeiras para desviarem desses obstáculos, podem vir a tombarem, em razão do desnível existente entre a calçada e o solo, e também, pelo fato de não haver rampa de acesso em toda a extensão da calçada.

Vale ressaltar, que a mensuração de largura obtida a partir da calçada supracitada, corresponde a $102 \mathrm{~cm}$, sendo que nas regiões onde estão implantados os hidrômetros, há um decréscimo dessa medida para apenas $77 \mathrm{~cm}$, atrapalhando tanto manobras individuais, quanto a condução por outras pessoas.

Além desse percurso (P10), há também outras residências adjacentes no local, que foram concedidas por programas assistenciais, porém sem a cautela e sensibilidade quanto à engenharia de acessibilidade. Essa questão favorece o margeamento das $\mathrm{PcD}$, pois aqueles cidadãos agraciados com as $\mathrm{Ha}-$ bitações de Interesse Social (HIS), são normalmente menos favorecidos frente à continuidade ou adição de algum benefício na edificação de suas moradias.

Esse panorama, aumenta ainda mais a necessidade de utilização de outros mecanismos auxiliares, como as Tecnologias Assistivas (TA) que além de promoverem a melhoria da capacidade funcional do sujeito, suscitam independência às dinâmicas sociais estabelecidas ou projetadas ${ }^{7}$.

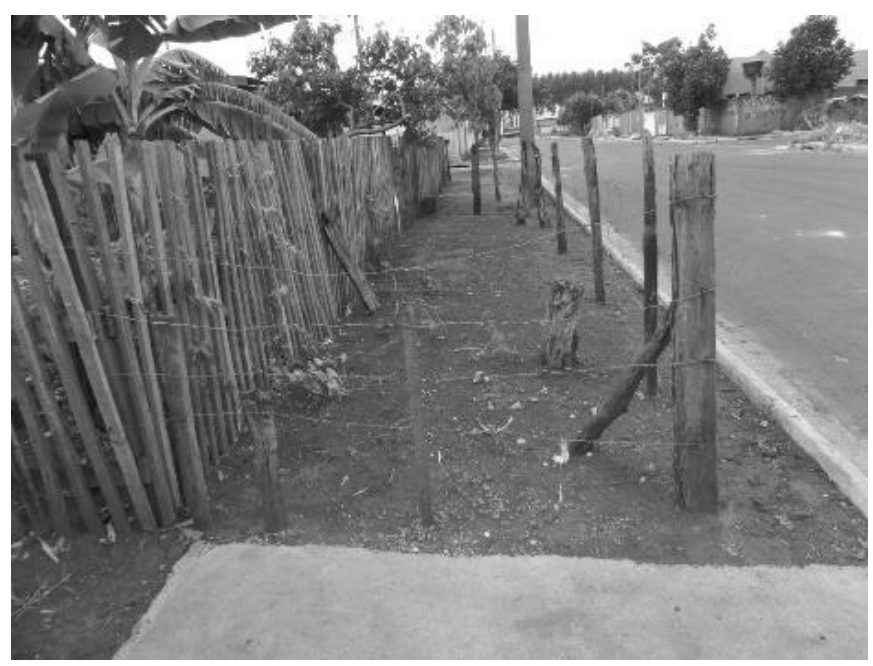

Figura 2. Obstáculo no trajeto P2. Novembro a dezembro de 2015. Tangará da Serra - MT, Brasil. 
Na figura 2, percebe-se que o espaço delimitado para término da pavimentação da calçada foi ocupado por uma cerca. Essa situação inviabiliza a utilização completa da calçada por algumas $\mathrm{PcD}$, visto que sua condição não permite a descida à via para continuação do percurso, tornando esse dispositivo público inutilizável. Esse obstáculo também está presente nos trajetos $\mathrm{P} 4$ e P8, remetendo à uma problemática de maior relevância.

A não pavimentação das calçadas remete à uma outra adversidade: seu uso indevido e desordenado como área de plantio. Parte dos moradores que habitam nesses derredores, apropriam-se desses espaços para o cultivo de árvores frutíferas e ornamentais, não tendo o devido cuidado em relação às complicações que suas atitudes trazem para as PcD e estrutura urbanística da cidade.

Como meio de conscientizar a população quanto a essa conduta, que constitui um obstáculo para a construção de uma sociedade ética, próspera e respeitosa, se encontram medidas educacionais ${ }^{8}$ como a cartilha de desenho universal, criada para promover a orientação da população referente às ações que interfiram na adaptação e mobilidade e direcionada à construção de espaços mais acessíveis e eliminação de barreiras?.

Demais estudos identificaram como adversidades a falta de conhecimento (35\%), de conscientização da população $(29 \%)$, apoio do governo $(16 \%)$, meios apropriados $(10 \%)$ e falta de interesse $(5 \%)^{10}$, aliadas à escassez de abordagens cientificas e proje$\operatorname{tos}^{11}$, que agravam a exclusão social. Esses fatores são de suma importância para o fortalecimento da inserção de $\mathrm{PcD}$ em meio à sociedade, pois parte da população desconhece os impactos decorrentes de sua ação, agindo esporadicamente em decorrência de hábitos culturais e não por negligência.

Para promoção da acessibilidade, compete às autoridades e órgãos públicos/privados o desenvolvimento de campanhas que visem a sensibilização da comunidade, disponibilizando recursos para a criação de projetos com enfoque nessa área e investindo na formação de profissionais que atuam em detrimento da inclusão social ${ }^{12}$. Nesse contexto, estão as ações preconizadas pela Vigilância Ambiental, Centro de Referência de Assistência Social (CRAS) e Universidades, desenvolvidas em redes, com ên- fase na mobilização social, englobando o acesso à informação e superação de desigualdades/vulnerabilidades, que caracterizam possibilidades de transformações sociais ${ }^{13}$.

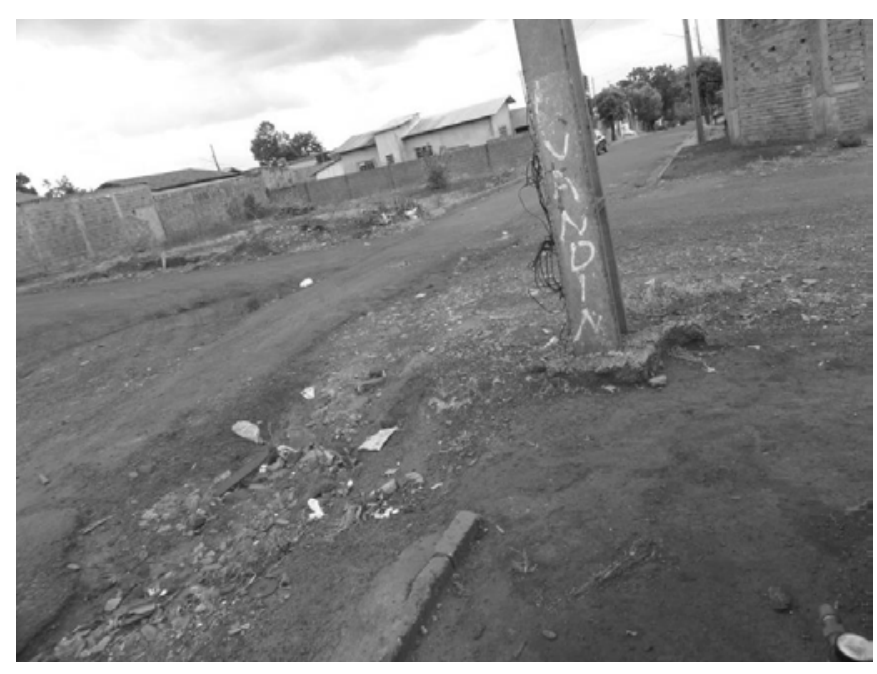

Figura 3. Ausência de calçada e pavimentação no trajeto $P 1$. Novembro a dezembro de 2015. Tangará da Serra -MT, Brasil.

Na figura 3, percebe-se que há uma delimitação para a construção de calçadas, contudo, há um poste de energia elétrica posicionado entre essa delimitação, o que sinaliza outro fator que coopera para a inacessibilidade. Nota-se também, vastos desníveis no caminho, bem como entulhos entre as depressões.

No período de aumento pluviométrico, a inacessibilidade se agrava, visto que todo solo não pavimentado se encharca, torna-se escorregadio, descompactado e inseguro para passagem de pedestres, complicando ainda mais a locomoção da PcD nesses trajetos, que muitas vezes são os únicos disponíveis para dirigir-se ao destino pretendido.

Normalmente, os bairros de periferia apresentam maior desordem urbanística se comparados a outros bairros. Isso se dá em decorrência da heterogeneidade da paisagem urbana, que reflete uma diversidade de produções espaciais projetadas a partir de métodos próprios e descontrolados, não atendendo às melhores condições necessárias de vida ${ }^{14}$.

Esta desordem é mais acentuada em bairros que dispõem de índice socioeconômico baixo, onde observa-se maior deficiência estrutural, remetendo à imprescindibilidade de um projeto urbano acessível como base para a promoção do desenvolvi- 
mento do espaço e para superação da desigualdade social ${ }^{14}$.

No trajeto P18, além do não calçamento, encontrou-se automóveis estacionados em meio à calçada, obstruindo completamente o trânsito de pedestres. Esse achado se configura como motivo para notificação, ora por não haver a devida autorização do órgão competente para a ocupação da mesma, ora por se enquadrar no âmbito de barreiras que impedem o tráfego.

Além disso, a problemática dos ferros-velhos, presentes no percurso P5 e P13, é um agravante desse aspecto e está presente em muitas cidades brasileiras. Os materiais desse tipo de comércio comumente ficam dispostos ao ar livre, em terrenos, vias públicas e calçadas, dificultando a circulação, e por corresponderem muitas vezes à estruturas perfuro-cortantes, robustas e/ou geradoras térmicas, ampliam os riscos de acidentes ${ }^{15}$. Sem desconsiderar outros problemas desses ambientes para os cidadãos, referentes ao contato facilitado com animais peçonhentos e vetores de doenças tropicais ${ }^{16}$.

As PcD assim como os demais cidadãos, possuem o direito de exercer um controle social efetivo. Esse, configura-se como a participação na gestão públi$c a$, fortalecendo a democracia e engloba a criação de canais de comunicação, bem como o acesso facilitado às informações, mecanismo fundamental para a consolidação da gestão democrática participativa. No âmbito da saúde, inclui a disponibilidade de portais individualizados, que abrangem os recursos repassados e as metas estabelecidas ${ }^{17}$, além da escuta e intervenções propostas pela sociedade ${ }^{18}$.

Historicamente, a luta de pessoas com deficiência pelos seus direitos tem sido constante. As reivindicações se fazem necessárias em grande parte dos ambientes, a começar por sua rua, que não dispõe de desenho universal. $\mathrm{Na}$ comunidade, apesar do desejo de envolvimento social, o que prevalece em muitas situações, são a intolerância à diferença e com isso, o isolamento social. Na estrutura e dispositivos do bairro, as PcD tem buscado incessantemente transporte adequado ${ }^{18}$, maior acessibilidade nas escolas e ambientes de lazer e práticas específicas às suas limitações, apoiadas por demais pessoas que fortalecem esse movimento ${ }^{19}$.
Profissionais de saúde, especialmente da enfermagem, por estabelecerem maior contato com os pacientes, são de fundamental relevância para superação de obstáculos e legitimação dos direitos das PcD. Suas ações de conscientização, permeadas pela disseminação de informações, constituem avanços significativos nesse entrave. Ressalta-se ainda como seu papel no cuidado a essas pessoas, a defesa pela liberdade e proteção da vida, bem como orientação aos familiares quanto ao seguimento do tratamento e reinserção social através do trabalho, lazer e exercício dos direitos civis ${ }^{20}$.

Para isso, devem seguir práticas exitosas como a "Roda do Quarteirão", estratégia desenvolvida no município de Sobral (CE) por profissionais de saúde, que visa 0 esclarecimento dos direitos das $\mathrm{PCD}$ por meio de medidas educativas com a comunidade, além de impulsionar o controle social. Os programas sobre funcionamento de órteses e próteses, atividades direcionadas na semana da pessoa com deficiência, seminários sobre inclusão, assistência social e capacitação para cuidadores de PcD são ações imprescindiveis que proporcionam maior qualidade e igualdade na vida dessas pessoas ${ }^{21}$.

\section{Considerações finais}

A partir do mapeamento dos trajetos das $\mathrm{PCD}$ à unidade de saúde da família, identificou-se vastos impedimentos que intensificam a inacessibilidade. Dentre eles, cita-se os entraves nas calçadas, como hidrômetros, automóveis estacionados, materiais de ferros-velhos, cercas e arborização inapropriada, bem como ausência de pavimento, revelando carências de adequações que contemplem o desenho urbanístico; mecanismo que propicia acesso e acessibilidade às pessoas com deficiência e aos demais cidadãos, nos ambientes e equipamentos.

Juntamente às $\mathrm{PcD}$ e a comunidade adjacente, os profissionais de enfermagem devem atuar por meio de práticas informativas e de conscientização, de modo que essa população exerça cada vez mais seus direitos, pois somente mediante o acesso ao conhecimento as $\mathrm{PCD}$ poderão efetivá-los. A começar pela descoberta e identificação de cenários para realizar suas reivindicações frente suas dificuldades, 
que podem ser intrínsecas e reconhecíveis apenas por quem as convive. Ademais, a inclusão dessa clientela em projetos de saúde contribui em demasia para o acolhimento integral e holístico em saúde.

Essa temática merece maior atenção, tanto de pesquisadores da academia como dos profissionais que atendem diariamente essa demanda. Explorando além do percurso à unidade de saúde, trajetos a outros locais de uso comunitário e coletivo, de modo a favorecer a difusão desses saberes por mais espaços de discussão e planejamento de estratégias que visem a acessibilidade.

\section{Contribuições individuais}

Nascimento VF participou da concepção do projeto, coleta de dados, análise, redação final e revisão. Gonçalves RA e Jesus WG participaram da coleta de dados. Graça BC, Terças ACP e Hattori TY participaram da redação final.

\section{Conflitos de interesses}

Nenhum conflito financeiro, legal ou político envolvendo terceiros (governo, empresas e fundações privadas, etc.) foi declarado para nenhum aspecto do trabalho submetido (incluindo mas não limitandose a subvenções e financiamentos, conselho consultivo, desenho de estudo, preparação de manuscrito, análise estatística, etc).

\section{Referências}

1. Associação Brasileira de Normas Técnicas. NBR 9050: Acessibilidade a edificações, mobiliário, espaços e equipamentos urbanos. Rio de Janeiro: 2015.

2. Amaral FLJS, Holanda CMA, Quirino MAB, Nascimento JPS, Neves RF, Ribeiro KSQS et al. Acessibilidade de pessoas com deficiência ou restrição permanente de mobilidade ao SUS. Ciência \& Saúde Coletiva. 2012;17(7):1833-40.

3. Siqueira FCV, Facchini LA, da Silveira DS, Piccini RX, Thuné E, Tomasi E. Barreiras arquitetônicas a idosos e portadores de deficiência física: um estudo epidemiológico da estrutura física das unidades básicas de saúde em sete estados do Brasil. Ciência \& Saúde Coletiva. 2009;14(1):39-44.

4. Ribeiro JP, Mamed SN, de Souza MR, Souza MM, Rosso CFW. Acessibilidade aos serviços de saúde na Atenção Básica do Estado de Goiás. Rev Eletr Enf. 2015;17(3):1-1 1. doi: $10.5216 /$ ree.v17i3.29436

5. do Nascimento VF. Acessibilidade de deficientes físicos em uma Unidade de Saúde da Família. Revista Eletrônica Gestão \& Saúde. 2012;3(3):753-66.

6. Rodrigues RC. Análise e tematização da imagem fotográfica. Ci Inf. 2007;36(3):67-76.

7. da Cruz DMC, Figueiredo MO, Matsushima AM, Rodrigues DS, Santos P. O trabalho e a tecnologia assistiva na perspectiva de pessoas com deficiência física. Rev Ter Ocup Univ. $2015 ; 26(3)$ :382-89. doi: 10.1 1606/issn.2238-6149. v26i3p382-389

8. de Carvalho AMC. A ecopedagogia no contexto educacional [trabalho de conclusão de curso]. Brasília: Universidade de Brasília; 2012.

9. Medola FO, Paschoarelli LC, Teixeira LC. A pessoa com mobilidade reduzida no ambiente domiciliar: demandas para o design universal e tecnologia assistiva [dissertação]. São Paulo: Universidade Estadual Paulista; 2015.

10. Domingues GS, Nishi BS, dos Santos PG. Análise da consciência dos alunos de administração acerca da política nacional de resíduos sólidos. Revista ADMpg Gestão Estratégica. 2015;8(1):111-23.

11. Dischinger $M$, Monteiro EC. Calçadas ribeirinhas no Pará, Brasil: considerações sobre as normas técnicas de acessibilidade para a realidade Amazônica. In: $7^{\circ}$ Seminário PROJETAR. 2015; Natal: Universidade Federal do Rio Grande do Norte; 2015.

12. Köhler AR, Pereira NC, Torgeski M, Winkelmann F. ASDEVI: um olhar pedagógico sobre a diversidade. Faculdade de Balsas. 2013;4(1):1-5.

13. Fonseca JRM, Parrão JA. Desafios de reconhecimento do trabalho do CRAS como política de proteção social básica no município de Sandovalina. Intertemas. 2015;9(9):1-20.

14. Aires JRA, Macedo YM, Maciel ABC. O uso do S.I.G. como ferramenta de gestão urbana no problema das construções irregulares: estudo de caso de Natal, RN, Brasil. Revista Geonorte. 2012;2(4):1683-93.

15. Carvalho SV, Heckert AL, Kunz GS. Modos de vida da população em situação de rua: inventando táticas nas ruas de Vitória/ES. Fractal, Rev Psicol. 2014;26(3):919-42. doi: $\underline{10.1590 / 1984-0292 / 1192}$

16. Pellissari B, Aguilar AMM, Lima MM, Brito WI. Aspectos socioambientais associados à ocorrência de dengue em um município do estado do mato grosso. $R$ Epidemiol Control Infec. $2016 ; 6(1): 1-6$. doi: 10.17058/reci.v6i1.6330

17. Bernardo R, Camargo TA, Lara ACHS, Prado O. Controle e transparência no modelo de organizações sociais de saúde 
do estado de São Paulo. In: IV Congresso CONSAD de Gestão Pública, 2013; Brasília. Brasília: Conselho Nacional de Secretários de Estado de Administração; 2013.

18. Aokia $M$, Oliver FC. Pessoas com deficiência moradoras de bairro periférico da cidade de São Paulo: estudo de suas necessidades. Cad Ter Ocup UFSCar. 2013;21 (2):391-98. doi: $\underline{10.4322 / \text { cto. } 2013.040}$

19. Aguiar ALO, Aquino SS. "Nada sobre nós, sem nós": movimentos sociais à luz das pessoas com deficiência. Revista Includere. 2016;2(1):315-18.

20. Jorge MS, Moraes VCO, Ventura CAA. Os profissionais de saúde e o exercício dos direitos humanos por portadores de transtornos mentais. Rev Eletr Enf. 2013;15(4):854-61. doi: $10.5216 /$ ree.v15i4.19746

21. de Carvalho AMF, Farias LMA, Linhares JM, Macêdo AM, Oliveira EN, Saraiva SM. Proativismo na saúde: o diferencial do PET na formação do enfermeiro frente ao cuidado à pessoa com deficiência. Sanare. 2015;14(2):75-78. 